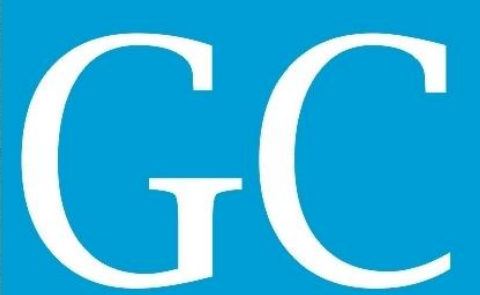

Revista Nacional de

Gerenciamento de Cidades

\title{
MÉTODOS ALTERNATIVOS DE DRENAGEM A PARTIR DA RETENÇÃO E INFILTRAÇÃO DAS ÁGUAS DE CHUVA NO SOLO, VISANDO A REDUÇÃO DAS ENCHENTES
} URBANAS

Fernanda Christine Beux ${ }^{1}$

Adacto Benedicto Ottoni ${ }^{2}$

\section{RESUMO}

É fato que os episódios de inundações em centros urbanos em decorrência de eventos chuvosos tem sido cada vez mais frequentes. A impermeabilização do solo, que impede a infiltração das águas de chuva no terreno, é um dos principais causadores deste aumento do escoamento superficial. Adicionado a isto, a implantação de tubulações de drenagem torna o escoamento até os pontos mais baixos da bacia mais rápido, diminuindo o tempo de deslocamento e aumentando os picos de vazão. Além de causar danos materiais, esses alagamentos também colocam em risco inúmeras vidas humanas. A fim de aumentar a infiltração das águas pluviais no solo e controlar o escoamento superficial é importante a adoção de técnicas alternativas de drenagem. Este trabalho aborda seis tipos de dispositivos de drenagem que permitem a infiltração das águas precipitadas (Bacias de Infiltração, Valas de Infiltração, Trincheiras de Infiltração, Poços de Infiltração, Bio-retenção e Pavimentos Permeáveis). Também relata três trabalhos de pesquisa a respeito de pavimentos permeáveis cujas conclusões apontaram eficiência no desempenho deste tipo de revestimento.

PALAVRAS-CHAVE: Contenção na fonte. Métodos alternativos de drenagem. Infiltração.

\section{ALTERNATIVE METHODS OF DRAINAGE FROM THE RETENTION OF RAIN INFILTRATION AND GROUND WATER, AIMED AT REDUCING URBAN FLOOD}

\footnotetext{
1 Engenheira Civil, Fundação Oswaldo Cruz (Farmanguinhos/ FIOCRUZ). Fernandabeux@gmail.com 2 Engenheiro Civil Sanitarista, UERJ - Universidade do Estado do Rio de Janeiro. adactoottoni@gmail.com
} 


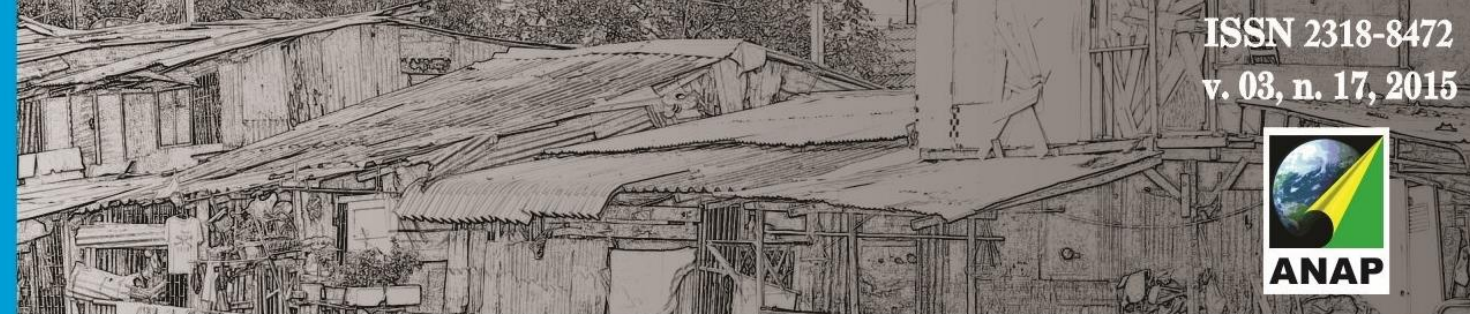

\section{Revista Nacional de}

Gerenciamento de Cidades

\section{INTRODUÇÃO}

Água é vida. Ela é fundamental para a manutenção da biodiversidade dos ecossistemas terrestres. Porém, aproximadamente $3 \%$ da água do planeta é doce. Acredita-se que num futuro próximo teremos conflitos pelo uso de água potável.

Neste contexto de possibilidade de escassez da água para consumo a gestão dos recursos hídricos torna-se prática fundamental. Esta gestão inclui um conjunto de medidas que devem ser implementadas nas bacias a fim de minimizar as alterações provocadas pela ação do homem.

As situações de enchentes e inundações surgem das crescentes áreas impermeabilizadas nas grandes cidades. Nestes momentos, além de todos os transtornos e mortes que as enchentes podem causar, é também muito comum a proliferação de doenças de veiculação hídrica em pessoas que tenham permanecido em contato prolongado com água ou lama contaminadas.

Um manejo adequado das águas pluviais priorizando métodos que controlem os deflúvios na fonte pode reduzir não só os alagamentos, mas também todos os danos causados tanto aos cofres públicos quanto aos cidadãos.

\section{METODOLOGIA UTILIZADA}

Foi desenvolvida pesquisa bibliográfica com vistas a identificar as características específicas e os condicionantes de projeto e execução de seis tipos de dispositivos de drenagem que permitem a infiltração das águas precipitadas (Bacias de Infiltração, Valas de Infiltração, Trincheiras de Infiltração, Poços de Infiltração, Bio-retenção e Pavimentos Permeáveis). Este trabalho também relata três experimentos de pesquisa realizados pelo Instituto de Pesquisas Hidráulicas da UFRGS, desde o ano de 2000, a respeito de pavimentos permeáveis cujas conclusões apontaram eficiência no desempenho deste tipo de revestimento. 


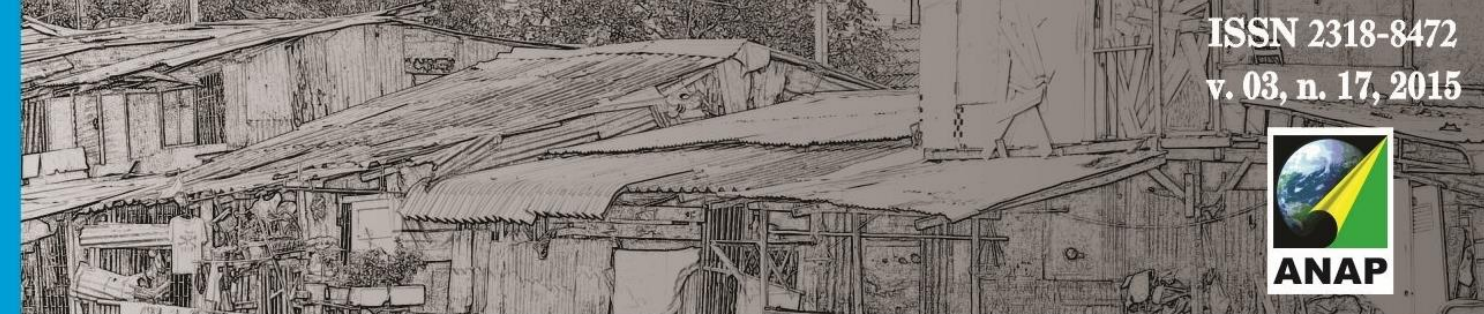

\section{Revista Nacional de}

Gerenciamento de Cidades

\section{Bacias de Infiltração}

IPH/DEP (2005) define bacias de infiltração como um terreno cercado por taludes que retem as águas de chuva até que estas infiltrem através da base e de seus lados. Normalmente são escavadas, porém pode-se utilizar pequenas encostas já existentes na área. Para sua adoção é importante se certificar da permeabilidade do solo e de que o nível do lençol freático seja suficientemente profundo, sendo indicado sua utilização em áreas de até 20 hectares; o uso do vertedouro é de caráter emergencial, pois o volume retido é liberado unicamente por infiltração.

\section{Valas ou Valetas de Infiltração}

As valas ou valetas de infiltração são dispositivos de drenagem lateral, frequentemente empregados paralelos às ruas, estradas, estacionamentos e conjuntos habitacionais, entre outros. Eles concentram o fluxo das áreas próximas e propiciam condições para uma infiltração ao longo do seu comprimento. Durante chuvas intensas o nível das águas se elevam e permanecem com água durante algum tempo, pois a infiltração é vagarosa. Desta forma, o volume das valetas deve ser grande o suficiente a fim de que não ocorram alagamentos (TUCCI, 1998).

Quando o escoamento no valo for maior que a capacidade de infiltração, essa estrutura trabalha tal qual um reservatório de detenção. Em períodos de precipitações escassas ou de estiagem, ele é mantido seco (TUCCI, 1998). O uso deste tipo de estrutura é praticável somente em áreas de solo permeável, e cujo nível médio do lençol freático seja inferior ao fundo da vala. 

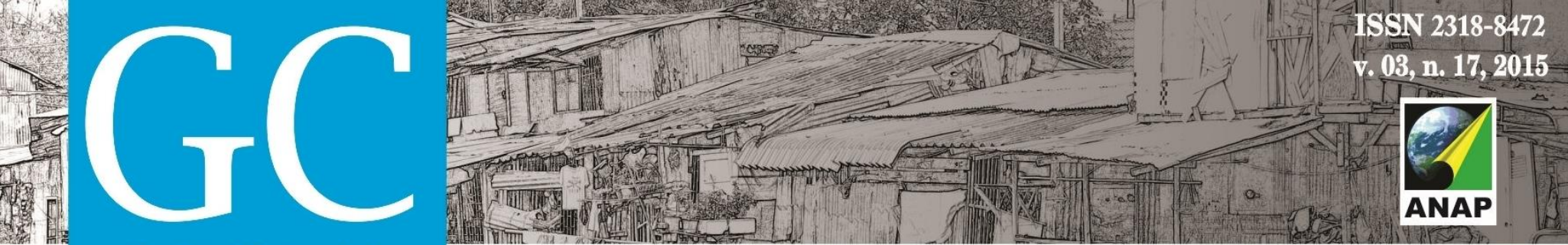

\section{Revista Nacional de}

Gerenciamento de Cidades

\section{Trincheira de Infiltração}

Trincheiras são escavações rasas preenchidas com pedras a fim de criar um armazenamento subterrâneo temporário que permita a infiltração das águas pluviais no terreno. Sua forma apresenta largura e profundidade reduzidas em relação ao comprimento (Figura 1). Na sua configuração ideal, recebem fluxo lateral de uma superfície adjacente impermeável, mas também pode receber entradas de fontes pontuais (CIRIA, 2007b).

Uma trincheira de infiltração pode ser usada como parte de um grande sistema de drenagem de águas pluviais, ou até mesmo, como integrante de um sistema de água de chuva para uma pequena área, tal qual uma fração de um telhado (PENNSYLVANIA, 2006).

Figura 1: Execução de uma trincheira

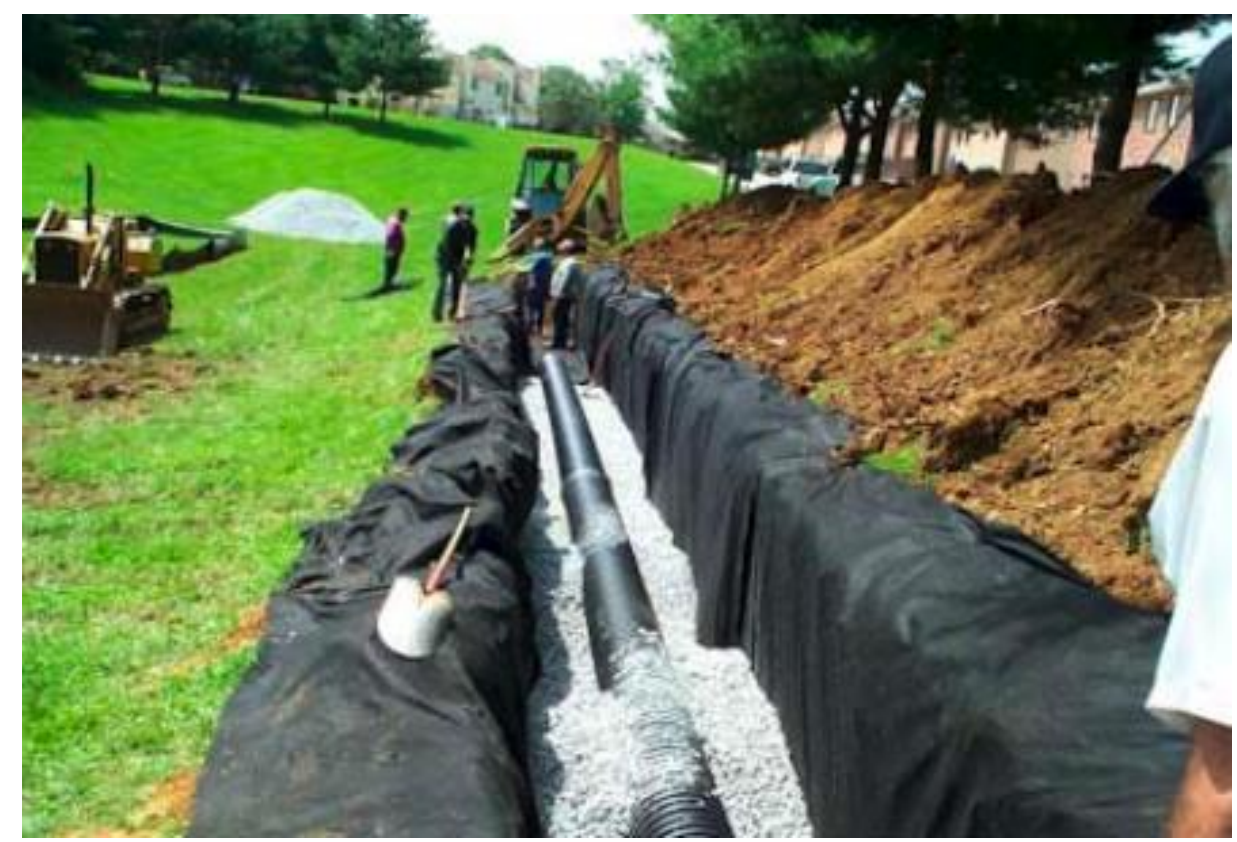

Fonte: CIRIA, 2007. 


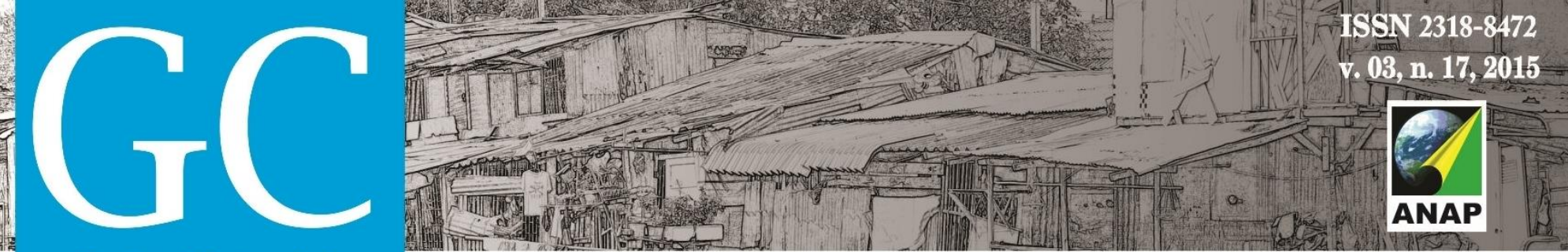

\section{Revista Nacional de}

Gerenciamento de Cidades

Figura 2: Vala de Infiltração

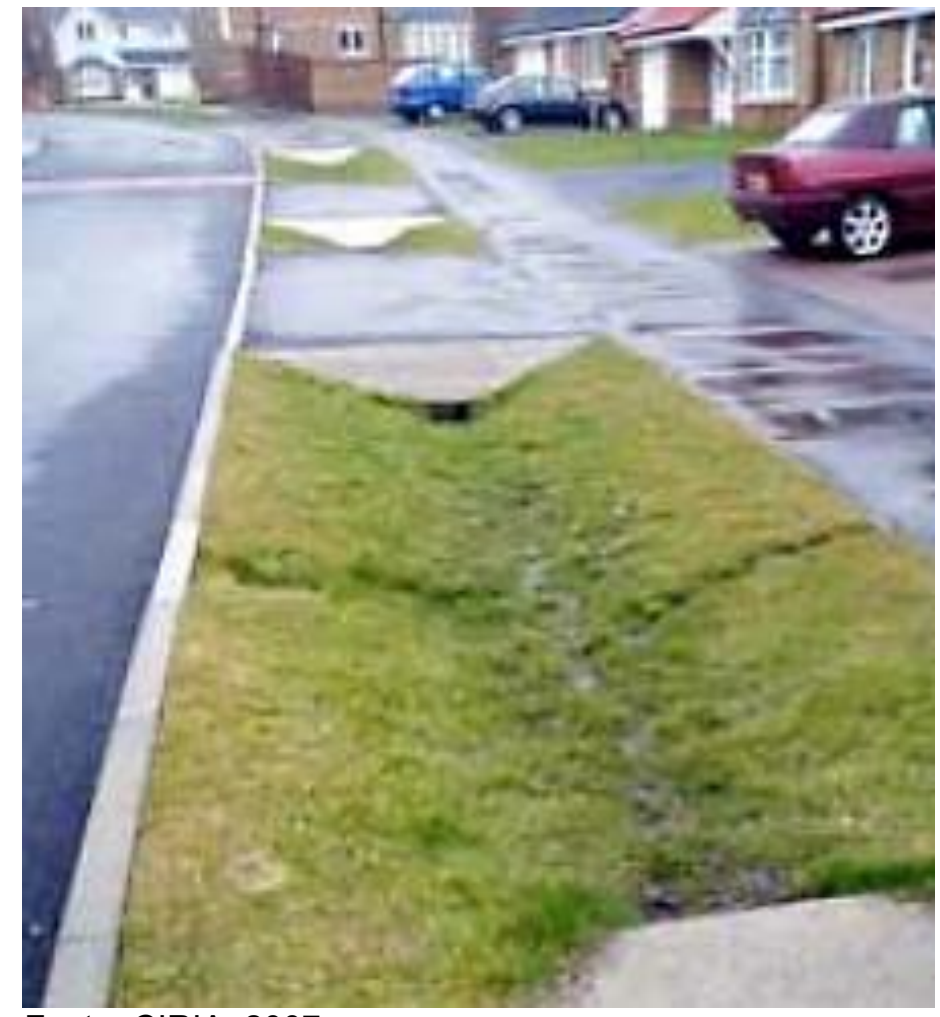

Fonte: CIRIA, 2007.

\section{Poços de infiltração}

Um poço de infiltração consiste em um pequeno fosso, geralmente preenchido com cascalho ou brita (figura 2.14). São concebidos para armazenar e propiciar uma lenta infiltração das águas no terreno e sua principal aplicação é no controle do escoamento das águas de chuva provenientes de telhados de edificações.

Podem tanto ser um poço escavado preenchido com agregados graduados envoltos em tecido geotêxtil, quanto uma câmara de armazenamento pré-fabricada, ou ainda uma seção de um tubo (PENNSYLVANIA, 2006). O geotêxtil tem a função de reter os finos que podem colmatar os poros do poço de infiltração mais rapidamente (PINTO, 2011). 


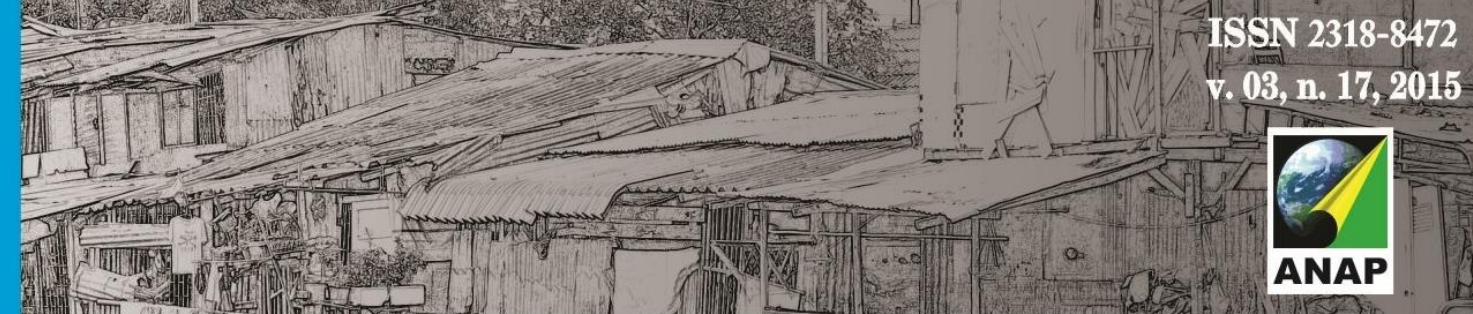

\section{Revista Nacional de}

Gerenciamento de Cidades

\section{Bio-retenção}

Sistemas de bio-retenção (também chamados de jardins da chuva) são depressões pouco profundas onde são plantadas vegetações nativas especialmente selecionadas a fim de tratar e reter as águas de chuva (Figura 3) (PENNSYLVANIA, 2006).

Figura 3: Exemplo Bio-retenção com extravasor

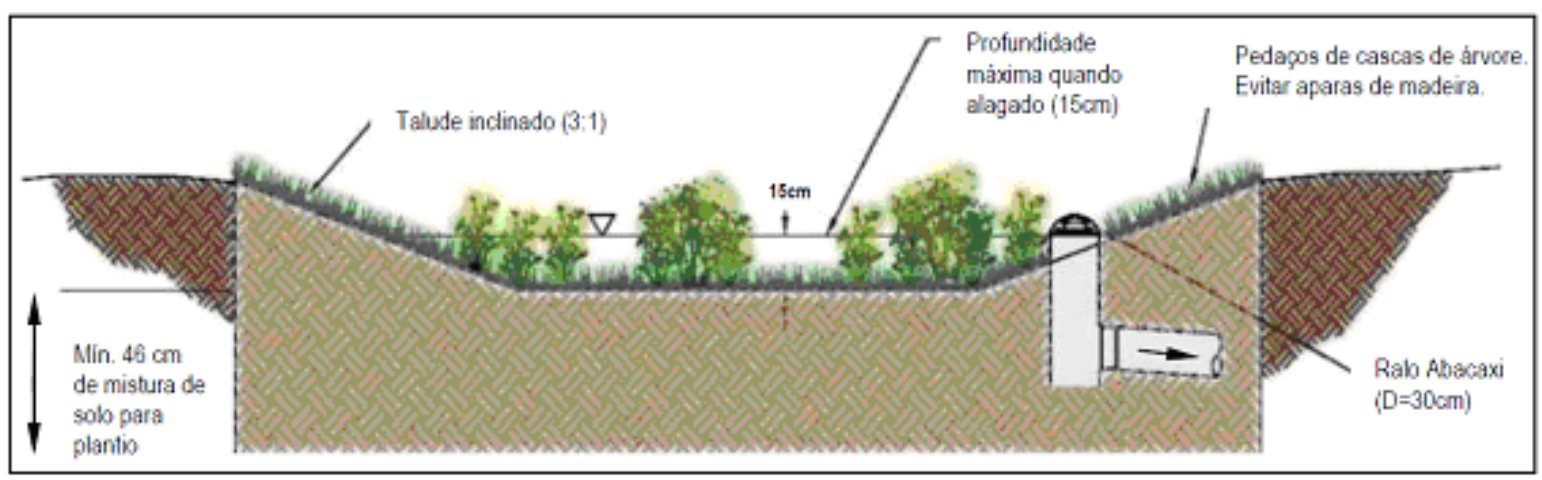

Fonte: PENNSYLVANIA, 2006

São geralmente estabelecidos nos baixios dos terrenos para que as águas precipitadas na bacia escoem até eles. Podem ser implantados com plantas de diferentes espécies e tamanhos e podem compor a paisagem natural da região onde estão inseridos. Neles, as águas provenientes das chuvas intensas empoçam na superfície e infiltram no solo. Por meio de adsorção, filtração e decomposição da matéria orgânica os poluentes são extraídos da água. Os elementos essenciais nesse sistema são as plantas, responsáveis pela retirada da água e dos poluentes (RIGHETTO, 2009).

Quando adequadamente projetadas, as técnicas de bio-retenção imitam os ecossistemas florestais naturais através de uma diversidade de espécies, densidade e distribuição da vegetação, e com a utilização de espécies nativas, resulta em um sistema resistente a insetos, doenças, poluição e alterações climáticas (PENNSYLVANIA, 2006). 


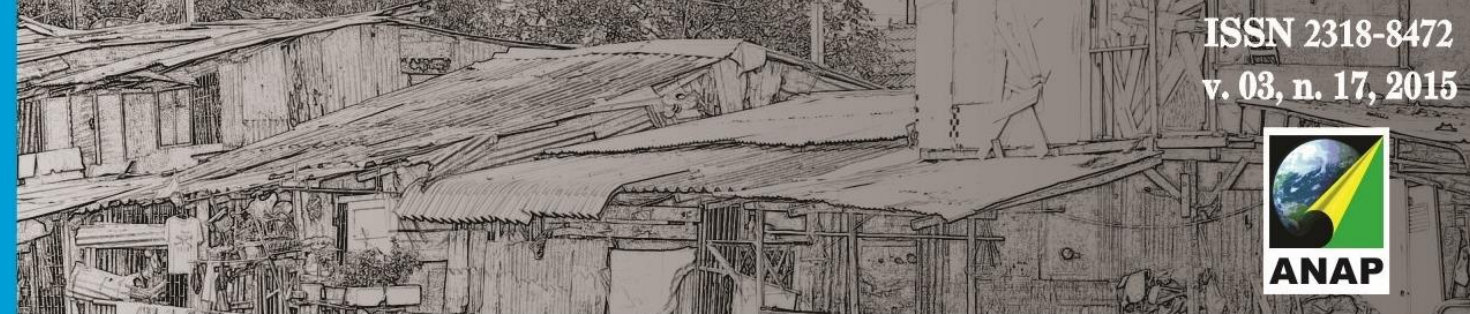

\section{Revista Nacional de}

Gerenciamento de Cidades

\section{Pavimentos Permeáveis}

Os pavimentos permeáveis têm sido utilizados nos Estados Unidos e Europa desde meados dos anos 70 (URBONAS, 2000). Este tipo de revestimento é uma opção à utilização das superfícies impermeáveis tradicionalmente adotadas, tal qual o asfalto e superfícies em concreto, utilizadas na pavimentação de áreas destinadas a estacionamentos de veículos, passeios públicos e até mesmo no interior de lotes.

São dispositivos através do qual o escoamento é desviado por meio de uma camada permeável para um reservatório subterrâneo de pedra, situado sob a superfície do terreno. Após, o escoamento armazenado gradualmente se infiltra no terreno ou ocorre uma lenta liberação por tubulações coletoras subterrâneas. O pavimento permeável se parece com os revestimentos convencionais. No entanto, ao contrário destes, ele contém pouca ou nenhuma quantidade de agregados finos. Assim, forma vazios que propiciam a infiltração (CHATTANOOGA, 2008 e Araújo et al., 2000). Ele pode ser constituído por (URBONAS, 2000):

- asfalto poroso;

- concreto poroso,

- blocos modulares

Os pavimentos permeáveis são tipicamente formados por três camadas:

- a primeira composta pelo pavimento permeável propriamente dito que pode ser asfalto ou concreto poroso;

- a segunda é o filtro, formado por agregados finos ou médios;

- e a terceira, o reservatório de pedras, composta por agregados graúdos. 


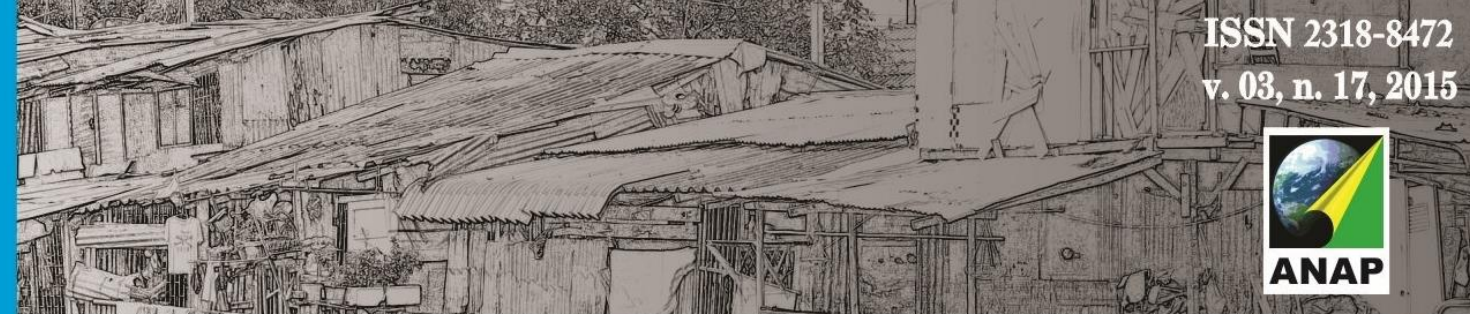

\section{Revista Nacional de}

Gerenciamento de Cidades

\section{RESULTADOS OBTIDOS}

Pela pesquisa bibliográfica desenvolvida confirmou-se que a adoção de métodos de drenagem que visem a infiltração das águas no solo podem reduzir consideravelmente os escoamentos superficiais, amortecendo os picos de vazões durante os eventos chuvosos. São procedimentos, que se utilizados somados a um conjunto de medidas, podem auxiliar na diminuição das inundações urbanas.

As características favoráveis mais relevantes quanto à implantação das Bacias de Infiltração, Valas de Infiltração, Trincheiras de Infiltração, Poços de Infiltração, Bio-retenção e Pavimentos Permeáveis é que estes dispositivos permitem:

- recarga de águas subterrâneas

- redução de cheias à jusante

- $\quad$ redução da vazão de pico das águas pluviais

Por outro lado, observou-se que a manutenção periódica é de extrema importância, a fim de aumentar a longevidade e manter o bom desempenho destes métodos não convencionais de drenagem. Caso não passem por uma manutenção periódica, exigirão reabilitação dispendiosa ou deverão ser substituídos a fim de manter a sua função.

No estudo sobre bio-retenção concluiu-se que a vegetação contribui significativamente para o manejo das águas pluviais. Com o acréscimo de áreas verdes, parte da água fica retida na terra e parte é consumida pelas plantas, suavizando o pico dos horários de chuva intensa. Adicionado a isso, a cobertura vegetal limita a possibilidade de erosão do solo minimizando assoreamento dos cursos d'água. A Figura 3 demonstra um exemplo típico.

A pesquisa bibliográfica realizada também buscou apontar, num estudo de três casos experimentais, a real eficiência de alguns tipos de superfícies 


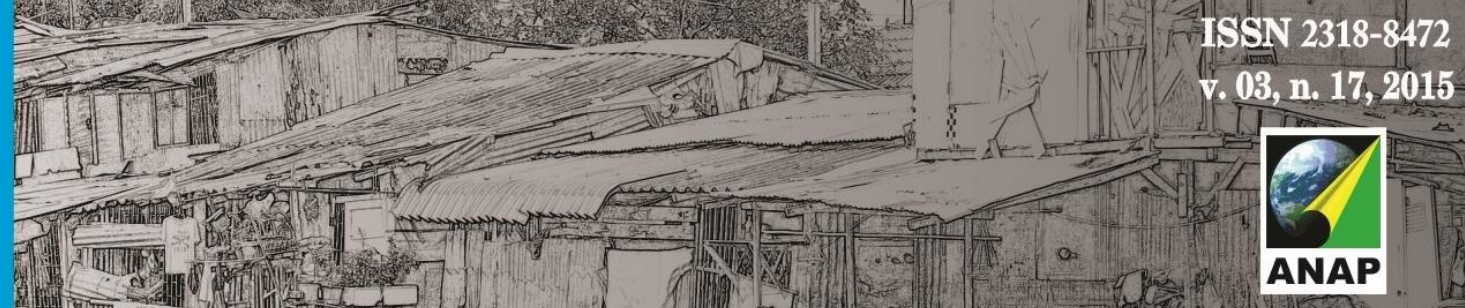

\section{Revista Nacional de}

Gerenciamento de Cidades

permeáveis. São opções aos pavimentos impermeáveis que vem sendo utilizadas no Brasil e que podem trazer ótimos resultados se utilizadas apropriadamente.

Figura 4: Seção transversal da estrutura do pavimento permeável.

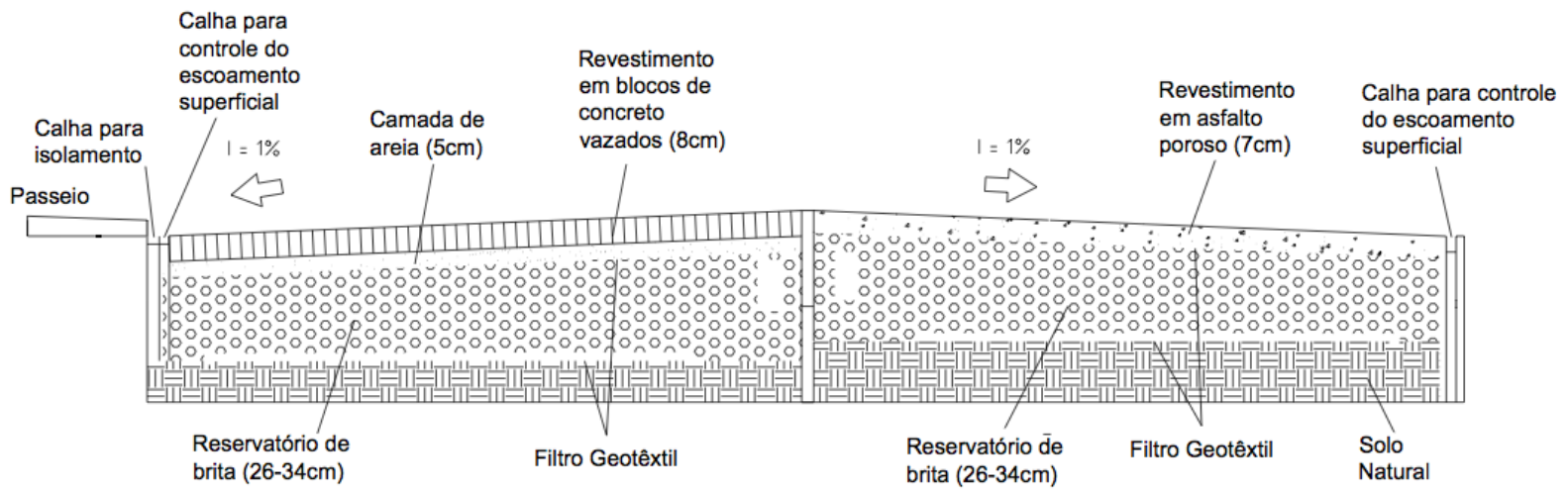

Fonte: ACIOLI, 2005

Os experimentos realizados pelo Instituto de Pesquisas Hidráulicas da UFRGS, desde o ano de 2000, destacaram a eficiência dos pavimentos de asfalto poroso e de blocos vazados para o controle na geração de escoamento superficial. O terceiro destes casos apresentados foi capaz de trazer mais certezas quanto ao real desempenho de pavimentos permeáveis e segurança aos profissionais no processo decisório de adoção deste tipo de revestimento. Este caso prático comparou o desempenho de dois tipos de pavimentos implantados em um estacionamento (Figura 4). Em metade da área implantou-se asfalto poroso, e a outra com blocos vazados preenchidos com pedriscos. Esta superfície de blocos foi a que apresentou melhor desempenho, mantendo uma ótima permeabilidade, mesmo após alguns anos sem qualquer manutenção. 


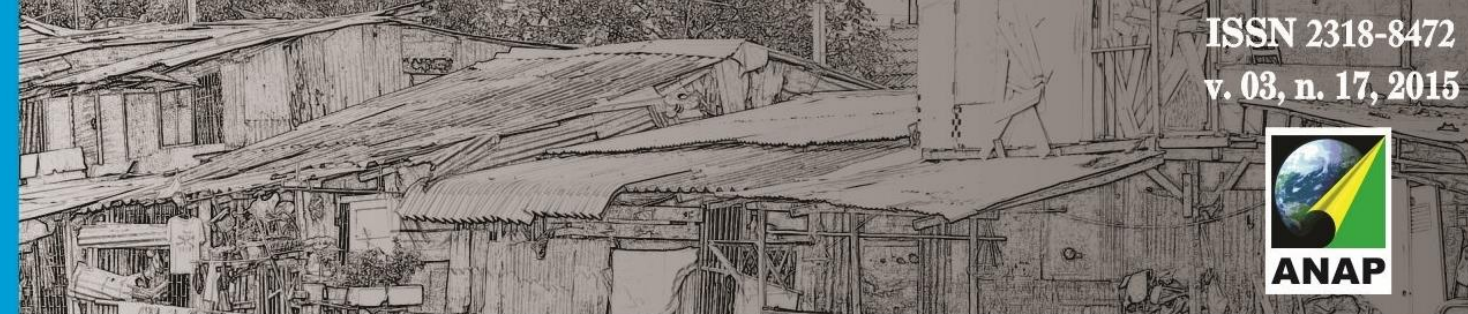

Revista Nacional de

Gerenciamento de Cidades

\section{CONCLUSÕES}

Um acelerado processo de urbanização desprovido do devido planejamento cria impactos ambientais como o aumento das inundações e a degradação da qualidade das águas pluviais. As ações do Poder Público no Brasil, buscando a solução destes problemas, estão quase sempre voltadas para adoção de medidas estruturais. São obras de drenagem que apenas transferem, por meio de tubulações, as águas precipitadas para áreas mais à jusante, sem avaliar globalmente as bacias.

Frente a isto, é primordial que o Poder Público, durante a elaboração dos Planos Diretores de Drenagem Urbana, considere o uso de dispositivos que retenham água nas bacias hidrográficas, permitindo a infiltração das águas e a redução dos escoamentos superficiais. Deve-se primar pela adoção de métodos não convencionais de drenagem que busquem o controle na fonte, tais quais os abordados neste trabalho (bacias de infiltração, valas de infiltração, trincheiras de infiltração, poços de infiltração, jardins de chuva e pavimentos permeáveis). Porém, é relevante mencionar que medidas compensatórias de drenagem urbana que utilizam técnicas alternativas a fim de reduzir ou controlar os excedentes pluviais, frutos da impermeabilização das superfícies, isoladamente não promovem o controle das inundações, apenas as amenizam.

Neste contexto, é vital a implementação de programas de monitoramento ambiental para garantir a proteção das Áreas de Preservação Permanente. Estas faixas de preservação de vegetação - geralmente localizadas ao longo dos cursos d'água, nascentes, reservatórios e em topos de morros - têm a função primordial de preservar os recursos hídricos. Também é importante o monitoramento permanente hidrométrico e de qualidade das águas dos rios, visando embasar as atuações corretivas de enchentes na bacia hidrográfica.

Para se aumentar a eficácia na gestão e controle das enchentes urbanas, é necessário que outras soluções complementares aos pavimentos permeáveis e a 
